\title{
Articulações entre leitura, produção textual e análise linguística no ensino de jovens e adultos
}

\section{Karla Renata de Lima}

Aluna da graduação em Letras da UFPE $e$ pesquisadora voluntária do PIBIC-CNPq-UFPE 2006-2007.

Resumo: A orientação teórico-metodológica mais recente para o ensino de português, defendida por Geraldi (1997b), é a de que as práticas de leitura, produção textual e análise linguística devem estar articuladas. No presente estudo, procuramos investigar se e como os professores promovem essa articulação, propondo leitura e reflexão sobre os recursos expressivos da lingua a partir da análise da escrita dos alunos jovens e adultos. Os resultados obtidos revelaram que algumas articulaçōes entre leitura e produção textual já fazem parte da realidade da turma de EJA observada, no entanto, a análise linguistica não é explorada nas aulas, o que limita a aprendizagem dos alunos.

Palavras-chave: língua portuguesa: ensino-aprendizagem-avaliaçẫo; avaliaçăo da aprendizagem; ensino de produçāo textual; educaçâo de jovens $\theta$ adultos

\section{LíVIA SUASSUNA}

Professora da UFPE - Centro de Educação - Dep. de Métodos e Técnicas de Ensino.

Résumé: Selon l'orientation théorico-méthodologique la plus récente pour l'enseignement du portuguais, soutenue par Geraldi (1997b), les pratiques de lecture, production textuelle et analyse linguistique doivent être articulées. Dans le présent travail, nous avons cherché si et comment les enseignants de jeunes et d'adultes font cette articulation, et particulièrement s'ils proposent aux élèves de la lecture et la réflexion sur les ressourses d'expression de la langue à partir de l'analyse de leur écriture. Les résultats ont montré que des articulations entre lecture et production textuelle sont effectivement utilisées dans la classe d'EJA (d'éducation de jeunes et d'adultes) étudiée, mais l'analyse linguistique n'est pas exploitée en classe, ce qui limite l'apprentissage des élèves.

Mots-clés: langue portugaise: enseignementapprentissage, didactique du langage, éducation des jeunes e des adultes 



\section{Introdução}

O presente estudo surgiu a partir de uma pesquisa mais ampla, intitulada Discursos sobre avaliação - o que se diz dos textos dos alunos em sala de aula e por nós desenvolvida no Centro de Educação da UFPE (PIBIC 2006-2007). A pesquisa tratava da avaliação em língua portuguesa, particularmente da avaliação da produção escrita, e tinha como principal objetivo, numa perspectiva teórica discursiva, ver como o texto do aluno, depois de lido pelo professor, retorna para a sala de aula. Uma de nossas hipóteses de trabalho era a de que, uma vez que no ensino de português predomina a visão de linguagem como código/sistema, a avaliação da produção escrita dos alunos seria reduzida a um trabalho de identificação e correção de erros gramaticais pontuais (principalmente de ortografia), não se levando em consideração aspectos discursivos da produção textual, tais como o gênero textual que deve ser produzido, as características da situação de interlocução, os objetivos pretendidos pelo autor, a escolha de determinados recursos expressivos, o tratamento temático, a informatividade do texto, entre outros.

O projeto de pesquisa estava dividido em três subprojetos. A presente investigação é decorrente do subprojeto 3: Discursos sobre avaliação-articulações entre leitura, produção textual e análise linguística. O propósito específico do subprojeto era observar se e de que modo a professora investigada (pertencente à Rede Municipal de Ensino do Município de Camaragibe - PE) articulava as práticas de leitura, produção de textos e análise linguística, considerando que essa é a orientação metodológica mais recente para o ensino de língua portuguesa. A articulação entre essas três práticas linguísticas foi investigada a partir do retorno dos textos dos alunos para a sala de aula, com o intuito de verificar se a professora conseguia realizar uma prática docente em que os diversos usos da língua (ler-escrever-escutar-falar) se integram com o eixo da 
reflexão (analisar a língua e seus recursos expressivos), em benefício da aprendizagem dos alunos.

\section{Fundamentação Teórica \\ 1.1 - $O$ que e como avaliar?}

Santos et al. (2004), lembrando a trajetória da educação de pessoas jovens e adultas no contexto educacional brasileiro, afirmam que a maioria das práticas desenvolvidas nessa modalidade de ensino foi marcada por campanhas emergenciais e assistencialistas.

Seguindo o mesmo raciocínio, Queiroz (2000, p .62) afirma:

É importante frisar que desde as primeiras iniciativas de classes noturnas voltadas para a alfabetização de adultos no Brasil, o ensino da nossa língua foi sempre direcionado para aquisição de um sistema de código alfabético, tendo como objetivo maior instrumentalizar os alunos adultos para os rudimentos da leitura e escrita.

Esse quadro começou a ser revertido a partir de 1958, quando o educador Paulo Freire propôs uma nova perspectiva de alfabetização, específica para adultos e centrada na politização dos educandos. Entretanto, para alguns estudiosos, Freire não priorizou a leitura e a escrita. Os seus ensinamentos enfocavam o conhecimento acerca do mundo, da realidade existencial, aprendido através do diálogo e das codificações das situações que representam essa realidade. No sentido freiriano, ser alfabetizado era tornar-se capaz de usar a leitura e a escrita como meio de tomar consciência da realidade e de transformá-la.

Para Leal (2004), o processo de alfabetização é concebido, hoje, como um período de aprendizagem de conceitos complexos, no qual o indivíduo desenvolve a capacidade de compreender e produzir textos, podendo, dessa forma, participar de eventos sociais mediados pela escrita. O domínio dos processos de 
produção e compreensão textual pressupõe não apenas a capacidade de codificação e decodificação, como também os conhecimentos acerca das situações de interação mediadas pela língua escrita, incluindo os conhecimentos textuais necessários à estruturação do texto e ao resgate do sentido. Logo, é de fundamental importância que, na escolarização inicial, sejam encaminhadas atividades de apropriação do sistema alfabético simultaneamente às atividades de apropriação dos usos e das funções sociais da escrita, com reflexões acerca dos diversos gêneros de textos que circulam socialmente.

Tendo isso em vista, ao tratarmos da avaliação da produção textual de jovens e adultos nas escolas, temos de considerar as atividades propostas, os critérios de avaliação adotados pelo professor, bem como o modo como os textos avaliados retornam para a sala de aula, buscando verificar se a prática pedagógica favorece a apropriação da escrita não apenas no que diz respeito ao sistema alfabético de escrita, mas também, e sobretudo, ao funcionamentos social do texto/discurso.

Hadji (1994) diz que a avaliação formativa (em oposição à classificatória) exige um triplo esforço de teorização: sobre o sujeito aprendente, sobre a situação didática e sobre o objeto ensinado. Nesse sentido, tomada a linguagem como discurso, seu ensino não se reduziria à descrição e memorização de regras de funcionamento da modalidade escrita padrão; tampouco a avaliação se reduziria ao cotejo da produção do aluno com um modelo de língua considerado ideal e correto.

Marcuschi e Viana (1997) sustentam que a concepção de linguagem adotada num processo de ensinoaprendizagem define e estrutura os objetivos a serem avaliados, os instrumentos e os critérios de avaliação. Mais do que cobrar do aluno respostas predefinidas sobre aspectos pontuais da língua, a partir de fragmentos de textos, em situações artificiais de interação, importa, antes de tudo, considerar que a linguagem se realiza na interação entre locutores socialmente situados, não 
podendo ser considerada independentemente de suas condições concretas de produção. $O$ discurso é lugar de contato entre o linguístico e o não-linguístico. Dentro dessa visão, deve-se tomar como centrais, juntamente com as formas de organização dos elementos (linguísticos) que constituem o texto, as formas de instituição dos sentidos. Além do mais, é preciso considerar sempre como característica essencial da linguagem a heterogeneidade (CARDOSO, 1999).

Fazer da aula de língua (e da avaliação) um processo legítimo de interlocução, devolver e aceitar a palavra do outro como constitutiva de nossas próprias palavras é uma exigência do próprio objeto de ensino, conforme diz Geraldi (1996). Isso implicaria mudanças significativas no que tradicionalmente tem sido definido como o conteúdo das aulas de português, levando-nos a fazer das próprias práticas discursivas dos alunos-sujeitos o objeto de ensinoaprendizagem. Deslocamentos ocorreriam também no âmbito do planejamento de ensino e nas relações alunoprofessor: em vez de blocos fechados de conteúdos, a elaboração de projetos didáticos e aulas que emergem da própria interlocução; em vez da relação unilateral entre quem sabe e quem não sabe, a busca de formas de convívio com a heterogeneidade.

Mayrink-Sabinson (2002) pensa que é exercendo práticas sociais de leitura e escrita que alguém viria a aprender a ler e escrever. Se isso é verdade, seria, então, bastante produtivo estruturar processos de ensino que tivessem como eixo a leitura e a produção de diversos tipos de textos enquanto materializações do discurso. Para Geraldi (1997a), alunos e professores aprendem e ensinam uns aos outros por meio de textos, para os quais vão construindo novos contextos, multiplicando os sentidos em circulação na sociedade. Acrescenta o autor:

Conceber o texto como unidade de ensino/ aprendizagem é entendê-lo como um lugar de entrada para este diálogo com outros textos, que 
remetem a textos passados e que farão surgir textos futuros. Conceber o aluno como produtor de textos é concebê-lo como participante ativo deste diálogo contínuo: com textos e com leitores (p. 22).

A sala de aula é um espaço privilegiado desse movimento interlocutivo, lugar de interações verbais e diálogo entre sujeitos e saberes. Aí cabe fazer das aulas de língua materna momentos em que interlocutores verdadeiros têm o que dizer, e o fazem por meio da língua tomada como atividade, processo criativo que se materializa pelas enunciações (CARDOSO, 1999).

O professor atuaria como um "disciplinador" da atividade do aluno no trabalho com o texto, para empregar um termo sugerido por Guimarães (1998). Uma de suas tarefas é criar situações interativas e pedagógicas, de modo a abrir espaços para o confronto entre os diferentes discursos/saberes e a reflexão sobre estes. Mais do que repassar informações a serem reproduzidas pelo aluno nos momentos de avaliação, o professor é aquele que orienta o aluno a correlacionar textos, lendo-os e produzindo-os numa cadeia interativa didaticamente organizada. Cabelhe garantir ao aluno o direito de participar de práticas sociais de leitura e escrita, de viver eventos variados de letramento, inclusive fora da escola (GERALDI, 1997a; MAYRINK-SABINSON, 2002).

\section{2 - Articulações entre leitura, produção textual e análise linguística}

Em termos da avaliação em língua portuguesa, importa lembrar que o fim último do ensino é formar cidadãos leitores e produtores de textos, em suas mais diversas configurações, através de três práticas articuladas, de acordo com a já citada sugestão de Geraldi (1996, 1997b): leitura, produção de textos e análise linguística. A leitura seria entendida como possibilidade de interlocução com o autor/texto, compreendendo, avaliando e criticando 
sua visão de mundo. A escrita diz respeito à capacidade de colocar-se como alguém que registra sua visão de mundo para ser lido por outros. Já a atividade de análise linguística teria como ponto de partida o uso da língua, enfocando aspectos linguísticos e discursivos desse uso, para, em seguida, permitir o retorno, com conhecimentos ampliados, às práticas linguísticas de leitura e escrita. Nessa situação de reflexão sobre os usos da língua, devem ser priorizados os níveis pragmático e discursivo de análise, funcionando os outros níveis (ortográfico e gramatical, por exemplo) como suportes da compreensão dos fenômenos estudados.

É relevante observar que a prática de análise linguística se aplica simultaneamente à leitura e à produção de textos, quaisquer que sejam estes (dos alunos ou dos autores trazidos para a sala de aula). Quanto à leitura, a análise linguística ajudaria na apreciação e compreensão dos muitos efeitos de sentido presentes no texto. Quanto à produção de textos, a análise possibilita a expressão da subjetividade do autor e dos sentidos que ele propõe ao seu leitor (o que também demanda apreciação e compreensão de efeitos de sentido). Assim sendo, a avaliação ganha muito em qualidade - diante de textos, lendo e escrevendo com nossos alunos, podemos superar a dicotomia certo $\mathrm{x}$ errado. Caso o aluno cometa erros - e é certo que os cometerá no processo de aprendizagem -, devemos encará-los como resultantes do nível de entendimento que ele possui da língua, de suas relações com as diferentes situações de enunciação com que se depara. Avaliar esses erros passa a ser promover um trabalho de reflexão sobre a língua e suas peculiaridades, uma atividade de construção/apreensão de suas regras de funcionamento.

Em se tratando especificamente de produção de textos, à luz de uma concepção discursiva de linguagem, temos que esse é um processo de retorno ao interindividual daquilo que, pela via das interações, se tornaria intraindividual (GERALDI, 1996). O trabalho do locutor é conjunto e revela um movimento contínuo: 
palavras alheias tornam-se próprias (do interindividual para o intraindividual) e, em seguida, o locutor as oferece para os outros (do intraindividual novamente para o interindividual). Na escola, através das atividades de escrita, mediadas e organizadas pelo professor, ampliamse as oportunidades de participação em processos interlocutivos. Saber escrever, muito mais do que o domínio de técnicas ou regras gramaticais, é engendrar uma proposta de sentido/leitura. Então, o ato de escrever pressupõe, conforme Geraldi (1995):

1. ter o que dizer;

2. ter a quem dizer;

3. ter razões para dizer;

4. constituir-seenquantolocutor/sujeitododizer;

5. dispor de mecanismos e estratégias do dizer.

Exige, ainda, que o produtor do texto tome decisões em vários níveis - semântico, pragmático, estilístico, discursivo, gramatical, textual e assim por diante. Os aspectos formais não são senão um dos componentes do texto. O que deve ser privilegiado são os processos de constituição do seu sentido. Segundo Cardoso (1999), um texto tem de valer sobretudo por aquilo que ele significa. O sentido do texto depende do próprio processo de escritura, bem como dos repetidos atos de leitura em que é atualizado a cada vez. Por isso, para Britto (1990), a redação e a leitura têm um aspecto dinâmico e interlocutivo; ambas são atos significativos e a própria condição de existência da escrita.

Nesses termos, em vez de absolutizarmos o texto do aluno como produto, "caçando" e corrigindo os erros aí presentes, podemos, tal como sugerido para a leitura, refazer com ele sua caminhada, problematizando aspectos linguísticos e discursivos daquela produção, chamando atenção para determinados usos de linguagem, questionando os efeitos de sentido produzidos.

Marcuschi e Viana (1997) acreditam que uma leitura atenta das estratégias e caminhos selecionados pelos 
alunos na elaboração de suas respostas pode favorecer a identificação dos obstáculos postos à sua aprendizagem, a problematização das práticas desenvolvidas em sala de aula e a abertura de caminhos para uma atualização da concepção de linguagem adotada e dos procedimentos metodológicos a ela associados. Propõe-se, aqui, então, deslocar o olhar do professor sobre o texto do aluno, desfazendo a ideia de que a intervenção didática é sinônimo de correção de erros ortográficos e gramaticais (CALIL, 2000).

\section{Metodologia}

A pesquisa foi realizada em uma escola da Rede Municipal de Ensino de Camaragibe. Na primeira etapa foi estabelecido contato com a Secretaria de Educação do município de Camaragibe, que ficou responsável pela indicação da escola observada, a qual oferece ensino fundamental de $1^{\text {a }}$ a $4^{\text {a }}$ séries e ensino de jovens e adultos (EJA).

A observação foi feita em uma classe de EJA do Módulo II; a turma é bastante heterogênea, composta por homens e mulheres com idades que variam dos 14 aos 65 anos e que residem, em sua maioria, no entorno da escola. Durante as observações, grande parte da turma mostrouse participativa, demonstrando interesse pelas aulas.

Realizamos a coleta dos dados no período de fevereiro a maio de 2007. Durante esse tempo, foram observadas vinte e três aulas de Português, com duração de duas horas cada. Utilizamos como instrumento de coleta de dados o registro descritivo das aulas observadas em um diário de campo. A análise de como foi explorada a articulação entre leitura, produção textual e análise linguística em sala de aula foi realizada a partir do levantamento de alguns elementos que envolvem a prática pedagógica da professora observada, como: as atividades de produção textual propostas aos alunos, os materiais de leitura utilizados nas aulas, o trabalho de análise linguística empreendido, os objetivos didático- 
pedagógicos que nortearam a prática da educadora e os processos avaliativos adotados.

\section{Análise dos Dados}

Analisemos agora algumas das situações didáticas observadas em sala de aula.

\section{- Situação 1: a falta de critérios para ordenar os conteúdos}

O primeiro dado relevante para a nossa pesquisa, constatado durante a coleta dos dados, diz respeito à falta de um projeto curricular adequado. A mistura de textos e atividades, associada à falta de critérios para ordenar os conteúdos, indicia que a professora não atentou para a importância da preparação da aula. Como vimos na fundamentação teórica, é essencial "correlacionar textos, lendo-os e produzindo-os numa cadeia interativa didaticamente organizada", visando à melhoria do aprendizado dos alunos. O exemplo que expomos a seguir retrata a falta de critérios para ordenar os conteúdos por parte da professora e a consequência de tal deficiência para o aprendizado dos alunos.

Na primeira aula observada, a professora trabalhou os gêneros textuais propaganda e matéria jornalística; dividiu os alunos em grupos e distribuiu jornais e cartolinas entre eles. Em seguida, solicitou que os alunos recortassem textos jornalísticos e propagandas e colassem nas cartolinas. Depois da leitura, oralmente, os alunos apontaram as diferenças entre os dois gêneros. Como esta aula antecedia as festividades carnavalescas, a professora aproveitou o ensejo e solicitou que os alunos elaborassem uma propaganda com o seguinte tema: "Escola Imaculada na folia", para divulgar a festa carnavalesca da escola. Os alunos leram as suas produções textuais em voz alta. A professora apontou o que faltou nas propagandas e prometeu trabalhar o gênero convite, visto que alguns alunos confundiram a propaganda da festa com o convite para a festa. 
Nessa situação didática ficou claro que a professora tentou articular as práticas de leitura e produção textual. Os alunos primeiramente foram apresentados aos gêneros textuais, aprenderam a identificá-los e só então a professora solicitou que eles desenvolvessem o gênero que tinham trabalhado (propaganda). No entanto, é importante salientar que, mesmo a professora faça leitura e produção textual, o trabalho restringe-se à forma dos gêneros textuais - ela não promove debate nem discussão sobre as posições assumidas nos textos, o que seria de extrema relevância para o aprendizado dos alunos. Como vimos na fundamentação teórica, a sala de aula é um espaço privilegiado para a realização de movimentos interlocutivos, lugar de interações verbais e diálogo entre sujeitos e saberes; por essa razão, cabe ao professor "criar situações interativas e pedagógicas, de modo a abrir espaços para o confronto entre os diferentes discursos/ saberes e a reflexão sobre os mesmos". No caso, foram justamente essas situações interativas e pedagógicas que deixaram de ser vivenciadas na aula observada.

Já a análise linguística não foi trabalhada pela professora nesse primeiro momento. Apesar de constatar que muitos alunos confundiram propaganda com convite, a professora não solicitou que os alunos reescrevessem seus textos. Como havíamos afirmado, avaliar erros é também promover um trabalho de reflexão sobre a língua e suas peculiaridades, uma atividade de construção/apreensão de suas regras de funcionamento. Outro aspecto a observar é o fato de a professora não ter retomado o conteúdo gênero textual convite nas aulas seguintes, o que significa que os alunos que apresentaram dificuldades na identificação da estrutura dos gêneros propaganda e convite provavelmente continuarão cometendo as mesmas falhas em suas futuras produções textuais. Ora, cabe ao professor, conforme já visto, atentar para os erros dos alunos e refazer com eles sua caminhada, problematizando aspectos linguísticos e discursivos daquela produção, chamando atenção para determinados usos de linguagem, questionando os efeitos 
de sentido produzidos. Essa seria a maneira eficaz de articular leitura, produção textual e análise linguística em sala de aula.

\section{- Situação 2: a dependência do livro didático}

Outro dado relevante para a nossa pesquisa deriva da dependência do livro didático por parte da professora da EJA. Durante a observação das aulas, constatamos que a professora não era a autora da aula e sim uma reprodutora do livro didático. Britto (1997), em seu estudo sobre o livro didático, afirma que o vínculo entre o $\mathrm{LD}$ e a prática escolar se explica por três razões principais: 1) a estruturação do sistema escolar na sociedade industrial de massa (que obriga a uma produção em série e faz o LD se impor como necessidade pragmática para as políticas de educação e os agentes pedagógicos); 2) o papel ideal e ideologicamente atribuído à escola (que faz o LD incorporar para si a tarefa de estabelecer uma ponte entre as instâncias produtoras do conhecimento e o processo pedagógico, e funcionar como formulador do currículo); 3) a visão do aluno como ser em formação (que dá origem a um processo de simplificação e padronização da exposição do conteúdo, na forma de um "didatismo reducionista", segundo o autor). Acreditamos que a dependência do livro didático por parte da professora da EJA se explica, ao mesmo tempo, pelos três fatores apontados por Britto. A seguir, expomos algumas situações didáticas para retratar o quanto a professora observada era dependente do livro didático.

\section{Exemplo 1}

Foi trabalhado o capítulo 1 do livro Conhecer e descobrir: língua portuguesa, matemática, história, geografia e ciências. 2a etapa. Maria Rita Costa de Souza, Wilma Jane Leckeviaus Costardi (orgs.). São Paulo: FTD, 2004. O capítulo 1, intitulado "Procurando emprego", apresenta anúncios e classificados com ofertas de 
emprego. A professora solicitou que os alunos lessem os anúncios em voz alta. O livro apresenta ainda um modelo de currículo. A professora leu com os alunos a definição de currículo apresentada pelo livro e passou a seguinte atividade de produção textual: Preencha um currículo com seus dados pessoais, formação, etc. No campo "objetivo pretendido" preencha com o que você pretende das aulas e da professora.

Aqui temos um problema que precisa ser comentado. A indicação errada do objetivo é mais um indício de que a professora não promove a reflexão linguística adequada sobre as propriedades dos gêneros textuais estudados. Ademais, a professora não aproveitou o conteúdo para promover um debate sobre emprego/ desemprego e não promoveu leituras de textos de outros gêneros sobre o tema. Durante essa atividade, constatamos mais uma vez que a professora trabalha as práticas de leitura e produção textual, entretanto, ignora a análise linguística em sua prática pedagógica. Os alunos fizeram a leitura de um gênero textual específico (currículo) e elaboraram um texto com base no gênero estudado. $O$ curioso é que essa foi a única produção recolhida pela professora. Todas as demais atividades de escrita citadas nessa pesquisa foram produzidas nos cadernos dos alunos, sem que tenha havido nenhum tipo de intervenção por parte da professora. Essa postura de não recolher as produções dos alunos foi um dado importante para a nossa pesquisa, que objetivava justamente examinar o retorno dos textos dos alunos para a sala de aula. Tal atitude nos levou a refletir sobre a prática de avaliação da professora, que caracterizamos como insuficiente para que os alunos consigam refletir sobre a escrita e suas particularidades e, por extensão, construir e ampliar seus conhecimentos sobre a língua materna.

\section{Exemplo 2}

Numa outra situação, a professora trabalhou um capítulo do livro intitulado "Vai faltar água?". Leu o 
texto em voz alta juntamente com os alunos e solicitou que os alunos respondessem às seguintes questões de interpretação de texto presentes no livro didático: 1) Qual a importância da água em sua vida? 2) Você acredita que a água no planeta vai acabar? Em seguida, a professora solicitou que os alunos escrevessem um pequeno texto respondendo à seguinte pergunta: o que você faz para evitar o desperdício de água?

\section{Exemplo 3}

A professora trabalhou um capítulo do livro sobre o gênero textual biografia. O livro apresenta uma biografia de Tarsila do Amaral e uma breve definição de biografia. A professora promoveu com os alunos a leitura em voz alta da biografia apresentada no livro e solicitou que os alunos respondessem às questões de interpretação de texto que o livro trazia sobre a vida e a obra de Tarsila do Amaral. Não houve atividade de produção de texto nessa aula.

\section{Exemplo 4}

A professora trabalhou um capítulo do livro sobre o gênero textual autobiografia. O livro apresenta uma autobiografia de Patativa do Assaré e uma pequena definição de autobiografia. A professora fez a leitura da autobiografia de Patativa do Assaré juntamente com os alunos e solicitou que os mesmos respondessem às questões de interpretação do texto do livro sobre a vida de Patativa do Assaré. Em seguida, a professora solicitou que os alunos realizassem a seguinte atividade de produção textual proposta pelo livro didático: “Agora que você já conhece os gêneros biografia e autobiografia escolha um deles e conte a sua história ou a história de alguém que você conhece."

Esses exemplos ratificam a dependência do livro didático por parte da professora. Constatamos, nas aulas observadas, que a professora não é autora da aula, o livro didático é seguido por ela como um verdadeiro manual e os textos produzidos pelos alunos são "esquecidos" em 
seus cadernos. Após as atividades de produção textual, a professora solicitava que alguns alunos lessem seus textos em voz alta, elogiava as produções desses alunos e passava para outra atividade. O questionamento que se pode fazer é: de que forma ela percebe se os alunos estão evoluindo na escrita? A resposta era óbvia: ela não avalia efetivamente a aprendizagem.

\section{Conclusão}

Embora a articulação entre leitura, produção textual e análise linguística seja a orientação metodológica mais recente para o ensino de língua portuguesa, esta ainda não é uma realidade nas aulas observadas em nossa pesquisa sobre avaliação na EJA. O que constatamos é que a professora promove atividades de leitura e produção textual, mas elas não são verdadeiramente articuladas. A análise linguística é desprezada na prática pedagógica da professora, quando, na verdade, deveria servir como suporte para o aprendizado de seus alunos. Verificamos, na observação das aulas, que a maioria dos textos produzidos pelos alunos continuaram em seus cadernos, sem nenhum tipo de intervenção da professora ou pedido de refacção. Levando em consideração que um dos aspectos fundamentais da prática de análise lingüística é a reescrita dos textos produzidos pelos alunos para que o professor possa trabalhar aspectos específicos do funcionamento da língua portuguesa - de acordo com o princípio de que é preciso fazer das próprias práticas discursivas dos alunossujeitos o objeto de ensino-aprendizagem -, podemos afirmar que os alunos da escola observada estão limitados em sua aprendizagem e que a articulação entre leitura, produção textual e análise linguística ainda é um desafio a ser vencido em algumas escolas/turmas da Educação de Jovens e Adultos. 


\section{Referências}

BRITTO, L. P. L. A redação: essa cadela. Leitura - teoria e prática, ano 9, n 15, p. 17-21, jun. 1990.

. A concepção de língua e gramática nas produções

didáticas. Leitura - teoria e prática, ano 16, no 29, p. 03-15, jun. 1997.

CALIL, E. Os efeitos da intervenção do professor no texto do aluno. Leitura - teoria e prática, ano 19, n¹5, p. 53-57, dez. 2000.

CARDOSO, S. H. B. Discurso e ensino. Belo Horizonte: Autêntica, 1999.

GERALDI, J. W. Da redação à produção de textos. In: CHIAPPINI, L. (coord. geral). Aprender e ensinar com textos. São Paulo: Cortez, 1997a, vol. 1 (Aprender e ensinar com textos de alunos), p. 17-24.

- Linguagem e ensino- exercícios de militância e divulgação. Campinas: ALB/Mercado de Letras, 1996.

. Portos de passagem. 3. ed., São Paulo: Martins

Fontes, 1995.

. Unidades básicas do ensino de português. In:

(org.). O texto na sala de aula. São Paulo: Ática, 1997b, p. 5979.

GUIMARÃES, E. Dimensões do texto. In: BASTOS, N. B. (org.). Língua portuguesa: história, perspectivas, ensino. São Paulo: Educ, 1998, p. 153-158.

HADJI, C. A avaliação, regras do jogo - das intenções aos instrumentos. 4. ed., Porto: Porto Editora, 1994. 
LEAL, T. A aprendizagem dos princípios básicos do sistema alfabético: por que é importante sistematizar o ensino? In: ALBUQUERQUE, E. e LEAL, T. (orgs.). A alfabetização de jovens e adultos em uma perspectiva de letramento. Belo Horizonte: Autêntica, 2004, p. 77-116.

MARCUSCHI, E. e VIANA, M. Dimensão social da língua portuguesa e avaliação de rede. In: MARCUSCHI, E. e SOARES, E. (orgs.). A valiação educacional e currículo: inclusão e pluralidade. Recife: Editora da UFPE, 1997, p. 2568.

MAYRINK-SABINSON, M. L. O que se ensina quando se ensina a ler e escrever? Ensina-se, mesmo, a ler e escrever? Leitura-teoria e prática, ano 20, n³8, p. 52-60, mar. 2002.

QUEIROZ, M. L. O ensino-aprendizagem de língua portuguesa na alfabetização de jovens e adultos. In: MOURA, D. (org.). Língua e ensino: dimensões heterogêneas. Maceió: EDUFAL, 2000, p. 61-66.

SANTOS, M. et al. Gêneros textuais na educação de jovens e adultos. Maceió: FAPEAL/EDUFAL, 2004. 